\title{
Popular Literary Tradition and the Localization of Early Chinese Films
}

\author{
CHEN Meng-xiong \\ Southwest University, Chongqing, China
}

\begin{abstract}
As a new form of artistic expression, film has gone through a history of more than 100 years in China. Focusing on the aesthetic taste of the underclass, popular literary tradition, which highlights appreciation habits of the citizen stratum, is the quintessence of Chinese traditional culture. Breaking through the mode of Western films, the early Chinese film, referring to artistic elements in story-telling script, fiction, and drama in Song and Yuan Dynasties, has created new film genres of "unofficial historical film" and martial-art film which are positive results of the localization of early Chinese films. Though the unofficial historical film failed in adapting the theme of popular literature, its groundbreaking significance is still worth approving.
\end{abstract}

Keywords: popular literary tradition, Chinese film, localization

\section{Introduction}

From the constant emergence of record-breaking Chinese films in 2015, it can be perceived that the creativity and comprehensive strength of Chinese home-made films have been on the rise, and it can also be realized that localization is required for Chinese film to obtain further development. For a long time, people, both in academia and general audience, tend to make comparative analysis between Chinese films and Western films,

...especially Hollywood films. They industriously explore and elaborate the representations of the influence of Western films on Chinese films, as well as the relation between Chinese films and Western Films, but pay little attention on the relation between Chinese films and Chinese traditional popular culture and literature. (DING, 2003, p. 45)

For Chinese film studies, there has been a long history of neglect of contemporary popular culture. And the academism has been more inclined to promote the "enlightening" literary films. Hence, the flesh-and-blood ties between Chinese film and its indigenous culture have been severed, and this explains why many films that were applauded by scholars had bombed at the box office. As a new form of artistic expression, film has gone through a history of more than 100 years in China. In most cases, excellent films which could be written into the film history of China are works that could not only wield expressive techniques of filming deftly, but also take into account both the appreciation taste of the audience and elements of its indigenous culture. The reason is

Once rooted into national culture, it is necessary for the film art to learn from the traditional literary and artistic forms in China, so as to reflect the inheritance of national tradition, and further to manifest the typical characteristics of traditional literature and art. (PENG, 2014, p. 76)

CHEN Meng-xiong, Ph.D. candidate, College of Liberal Arts, Southwest University. 


\section{Inheriting the Narrative Mode From Popular Literature}

"The highbrow art and literature" and "the lowbrow art and literature" are two mainlines in Chinese literature, together creating magnificent Chinese literature. However, all historical writing is under the command of those who possess the discourse hegemony. With the conventional thinking of despising popular literature, scholar officials laid aside intentionally the tendencies of literary creation that were "aiming at the vulgar taste" or "unrelated to moralization". But, this could not impede the development of popular literature. As WANG $\mathrm{Xi}$-lian in Qing Dynasty wrote in the Introduction of Remarks on the Story of the Stone,

In terms of fiction, is it of no importance? ...For those who have a thorough understanding of it, it could have the same importance as poem and essay. ... Though the cultural levels of fiction and poem and essay are different, the moralization function of them could be the same. (HUANG \& LUO, 2009, pp. 597-598)

WANG Xi-lian put forward his predecessors' viewpoint at first that fiction is of no importance. Then he turned to claim that for those who have a thorough understanding of them, it could have the same importance as poem and essay. In this way, he admitted the rationality of the existence of fiction, and recognized indirectly the humanistic value of popular literature. Moreover, he argued that although fiction and poem and essay belonged to different cultural levels, they could perform the function of moralization equally. As one of the genres, fiction, along with various local dramas, constitutes Chinese popular literature, the source of which could be dated back to folk ballads collected by early poem collectors. And after the rising of Sujiang-bianwen (the recitation and singing of the transformed sacred texts) in Tang Dynasty, Chinese popular literature stepped into a period of rapid development. In Song Dynasty, driven by the composite force consisting of imperial examinations, politics, and other elements, a large number of intellectuals joined into the folk, which brought forth the down-shifting of culture.

Affected by the down-shifting of culture, the main body of literature began to reflect, besides the identity and humanistic quality of traditional intellectuals, the taste of folks, and started to focus on the value of popular culture, which led the main power in the literary world to enter the era of non-elite writing. Hence, popular literature gained a footing in the literary world and changed the dominating position of serious and elegant literature. (SHEN, 2014, p. 64)

The development of popular literature brought forth many "target-like figures" (usually some famous images in popular literature, to whom folks were willing to attach more stories and plots). The formation and advancement of these figures had been attributed to a joint effort of numerous popular literature works through the ages. For example, The Cases of Sigong made in 1931 by Shaw Brothers (Hong Kong) Limited, also known as Five Women and Seven ZHENs, was originated from a detective-style fiction of the same name in Qing Dynasty. In this period, the Shaw Brothers produced a good deal of films, including The Hongwu Emperor, Emperor Qianlong Tours the South Part, Princess Iron Fan, The Lovers, Madame White Snake, and The Three Smiles. All these films had inherited folks' taste-oriented narrative principle from popular literature, and they had been shot with fixed cameras, paying little attention on the filming techniques of camera language and lighting effects, or the artistic technique of space configuration. It could even be said that Chinese film in this period is basically a copy of Chinese drama, just changing the stage into the camera. As a scholar pointed out:

When we get back to historical sites, we will find that Madame White Snake is not so "a film", or is not "a film" at all. In terms of the plot, it is almost the same as The Legend of White Snake presented on the drama stage, even the scenes 
of filming are the same with the drama. More precisely, this film is the starting point of the transformation from "drama" to "film". (BAI, 2013, p. 34)

Seen from the development of Chinese film, most of Chinese filmmakers in this period regarded film as an extension of drama, and managed to retain the narrative technique of drama in film as much as possible. In terms of noumenal characteristics of films, the essential problem of Chinese film then was that the narrative mode of filming had not broken the limitation of the story logic, and still failed to influence the logic through narration.

Giving greater prominence to the popularized aesthetic taste of popular literature according to the then consumer groups of film, the early Chinese film basically inherited the omniscient and omnipotent narrative mode from traditional popular literature. In the Madame White Snake produced by the Shaw Brothers, the defender image of Fa-hai and the everlasting love between XU Xian and BAI Su-zhen had all been retained, in line with the traditional themes of mixing Buddhism and Taoism and prohibitive love between human and snake. However, the Green Snake made in 1993, also based on The Legend of White Snake, "found an innovative point in the interstices of traditional text" (HUANG, 2000, p. 209). Adapted from a fiction by LI Bi-hua, this film viewed the emotional entanglements between XU Xian, BAI Su-zhen, Fa-hai, and Xiao-qing in the perspective of modern people, completely surpassing the framework of traditional popular literature. Utilizing the narrative perspective of dual omniscience to create conditions for the arrangement of film plots, this film presented thoroughly the emotional entanglements through the clear-sighted onlooker-Xiao-qing, and reconstructed the defender image of Fa-hai. By contrast, it could be found that the narrative mode of popular literature was its bases of emotional connotation and artistic characteristics. Since the traditional modes were broken, the development of Chinese film had presented more and more westernized characteristics. With the aid of switching narrative perspectives, the audience was able to see more complicated emotional entanglements of characters. Some scholar argued,

The attraction of the Green Snake lies in, rather than revealing the truth of love, the deliberately mystifying of LI Bi-hua, which sophisticates a simple folklore into a story full of diversified desires. Appearing to point out the mutual deception between men and women, this film, in fact, conceals the obsession with and the longing for love in the insights into worldly affairs in a cynical way. (CHEN, 2000, pp. 213-214)

The success of LI's literary creation lies in that, on inheriting the tradition of popular literature, she had boldly adopted the non-dramatization narrative mode, which opened the way for the transformation from The Legend of White Snake to the Green Snake. Throughout the development history of Chinese film, it is necessary for us to realize that, the early Chinese film had progressed along the road of inheriting traditional popular literature, including traditional themes, characters, and narrative technique, and Chinese films did not present the tendency of surpassing the tradition in narration until they had been more and more affected by modern culture.

\section{Transforming the Theme of Popular Literature}

Fiction and Chinese drama are two main literature genres in Chinese popular literature. They can be subdivided into song, ballad, tune, speech, story-telling script, local drama since Song and Yuan Dynasties, popular telling-and-singing forms, such as Bian-wen (the recitation and singing of the transformed sacred texts), Tan-ci (storytelling to the accompaniment of stringed instruments), and Gu-ci (storytelling to the accompaniment of drums), and even miscellaneous works like folklore and joke. Since the publication of History of Chinese 
Popular Literature by ZHENG Zhen-duo, the long-stalled popular literature had attracted more and more attention. Inheriting the tradition of popular literature is the common feature of the filmmaking of early Chinese film companies represented by the Shaw Brothers. Nevertheless, they had, rather than been contented, strived to find a way for the nationalization of Chinese film to make Chinese film industry bigger and stronger. And their motivations came from two parts: On one hand, they had to compete with foreign companies which were dominating Chinese film market then, and on the other hand, they wanted to expand more survival space for Chinese film industry. So it can be said that the localization of Chinese film has begun since the 1920s and 1930s. Among many forms of popular literature, fiction, and Chinese drama, by virtue of their relatively complete plot, rich emotional connotation, and certain depth in thinking, had won the attention and recognition of the audience. Through creative transformation, numerous original popular literary works had been put on screen, especially in "unofficial historical films" made by the Shaw Brothers earlier, which had provided early Chinese films abundant artistic elements during the process.

Absorbing the content and plots in folktale, classical fiction, and local drama, the "unofficial historical film" had made popular literature the main framework and achieved the visualization of popular literature. The first "unofficial historical film" is Chuang Tze Tests His Wife produced by Asiatic Concept, in which the characters are performing in costume of Qing Dynasty. Then, inspired by Rearranging the National Heritage Movement advocated by HU Shi, the Activity and Film Department of the Commercial Press adapted ZHENG Yuan-he Sings in Distress into the film Lian-hua-luo, Shan-hu, and The Taoist from Lao-shan Mountain in the Strange Stories From a Chinese Studio into The Flesh Soup and A Dream in Qing-Xu respectively. However, most of the advancement of "unofficial historical film" should be attributed to Tien-1 Motion Picture Company established by the Shaw Brothers. The success of "unofficial historical film" in this period comes largely from the audience's tiredness with the film market full of social problem films and love films. It is necessary for film companies to introduce new elements for survival in intense market competition. As BAO Tian-xiao said, "the prosperity of Chinese film industry can only depend on historical film rather than the present so-called love film presenting the bashful affection between actors and actress" (BAO, 1925, p. 12). Even today, these words sound striking still. The discussion on historical films started from 1925 had not only cleared up the inundation of love films, but also infused the genes of traditional culture into the spiritual connotation of early Chinese film.

Focusing on the theme of film, it can be found that the unofficial historical film usually uses family ethics and love between men and women as the essential theme, that is, the traditional pattern of gifted scholars and beautiful ladies. Hence, the unofficial historical film, which generally aims to present the love of contemporary people with the help of historical background, is not equal to the historical film. On one hand, the narrative framework of the unofficial historical film surging in that period was based on the stories in Tang Legends, Song Talking, Yuan Operas, and Ming Dramas. On the other hand, the then filmmakers strived to add modern elements of pursuing love into traditional theme of love films. Take YANG Nai-wu produced by Tien-1 Motion Picture Company as an example, it is based on a story in the Four Sensational Cases of Late Qing Dynasty which has had extensive mass basis in folks already. But the film have been, rather than limited to the original theme of appealing for redressing, complemented appropriately by affective factors which had provided the audience more diversified emotional imagination. And among other films screened in the same period, films adapted from traditional martial-art fiction and The Swordsman of Shu Mountain by Huanzhu-Louzhu had received praise from 
the audience as well. However, elements of traditional Chinese drama can still be found in films in this period, such as costume in Ming Dynasty and retained scenes and acts. Therefore, films in this period have not been of modern significance yet.

And the Burning Paradise in Hell produced by Star Film Company in 1928 can be said to be a watershed for the development of the early unofficial historical film. Instead of regarding dramas in Song and Yuan Dynasties as the theme as usual, this film has placed the martial-art elements in Tang Legends into completely fictional historic space and tried to use modern special effects to improve the artistic level of the film. In this film, the audience have appreciated the power of sword arc and position tactics for the first time, and have been impressed by the special effects which enable the finger to give off a beam of white light that has the magic power to drive the sword to fight with the enemies unconditionally. DONG Ke-yi, the photographer of this film, applied creatively the method of "roof-contacted" to the filming, combining the roof of Hong-lian Temple, which had been drawn on the glass plate, with the setting of the Temple without the roof to compose skillfully the complete and glorious architecture of Hong-lian Temple. Also, by means of combining real person with cartoon character, this film had been able to present the fight scenes with blaring sword arcs. Moreover, the advanced techniques in this film enabled the shape of the figures to enlarge and shrink on screen easily, and even realized the special effects of multiple figures. Based on the theme and the narrative mode of popular literature, the unofficial historical film had been added elements of pursuing love to its development. When the film market was inundated by love films, the timely appearance of unofficial historical film expanded the survival space for early Chinese film. And when the filmmakers realized that the independence of Chinese could not depend purely on Rearranging the National Heritage and inheriting the mode of Chinese drama, they turned to promote the martial-art film energetically and became the successor and promoter of unofficial historical film.

\section{Conclusion}

According to the strict classification of the film types, we are inclined to position it as unofficial historical film, rather than historical film. And the reason is that the seriousness of historical film basically rejects the main makers' creativeness in the theme setting. Such films like The Lovers, Pearl Pagoda, and Madame White Snake are just love films with a mask of history. Therefore, though the unofficial historical film failed in adapting the theme of popular literature, its groundbreaking significance is still worth approving.

\section{References}

BAI, H. Y. (2013). Tradition of the Shaw Brothers in the film of The Legend of White Snake: Centering on Madame White Snake produced by Tien-1 Motion Picture Company. In Film art. Beijing: China Film Association.

BAO, T. X. (1925). Discussion on historical films. In Stars special. Shanghai: Star Film Company.

CHEN, G. Q. (2000). Literary Hong Kong and LI Bi-hua. Taiwan: Cite Publishing Ltd..

DING, Y. P. (2003). The tradition of popular culture and the 20th century Chinese film. In Film art. Beijing: China Film Association.

HUANG, L., \& LUO, S. H. (2009). Collation and annotation on the collection of criticism on novels of past dynasties. Nanchang: Baihuazhou Literature \& Art Press.

HUANG, W. L. (2000). Lively and diversified Hong Kong literature. Hong Kong: Chinese University Press.

PENG, L. Z. (2014). From the talking art in Song and Yuan Dynasties to the early "Unofficial Historical Films of the Shaw Brother". In Contemporary communications. Urumchi: Xinjiang Autonomous Region Press Association.

SHEN, S. Q. (2014). The delamination and literature transformation of Bachelor Stratum at the turn of Song Dynasty and Yuan Dynasty. In Literary review. Beijing: Literature Research Institute at the Chinese Academy of Social Sciences. 